\title{
Land Cover Mapping using Digital Earth Australia
}

\author{
Richard Lucas ${ }^{1, *}$, Norman Mueller ${ }^{2}$, Anders Siggins ${ }^{2}$, Christopher Owers ${ }^{1}\left({ }^{\circ}\right.$, Daniel Clewley ${ }^{3}$, \\ Peter Bunting ${ }^{1}{ }^{(\mathbb{D}}$, Cate Kooymans ${ }^{2}$, Belle Tissott ${ }^{2}$, Ben Lewis ${ }^{2}$, Leo Lymburner ${ }^{2}$ and \\ Graciela Metternicht ${ }^{4}$ (D) \\ 1 Department of Geography and Earth Sciences, Aberystwyth University, Aberystwyth, Ceredigion, \\ Wales SY233DB, UK; cho18@aber.ac.uk (C.O.); pfb@aber.ac.uk (P.B.) \\ 2 Geoscience Australia/Digital Earth Australia (DEA), GPO Box 378, Canberra, ACT 2601, Australia; \\ norman.mueller@ga.gov.au (N.M.); anders.siggins@gmail.com (A.S.); cate.kooymans@ga.gov.au (C.K.); \\ belle.tissott@ga.gov.au (B.T.); ben.lewis@ga.gov.au (B.L.); leo.lymburner@ga.gov.au (L.L.) \\ 3 Plymouth Marine Laboratory, Plymouth PL1 3DH, UK; dac@pml.ac.uk \\ 4 School of Biological, Earth and Environmental Sciences, the University of New South Wales, High Street, \\ Kensington, NSW 2052, Australia; g.metternicht@unsw.edu.au \\ * Correspondence: rml2@aber.ac.uk
}

Received: 31 May 2019; Accepted: 29 August 2019; Published: 1 November 2019

Abstract: This study establishes the use of the Earth Observation Data for Ecosystem Monitoring (EODESM) to generate land cover and change classifications based on the United Nations Food and Agriculture Organisation (FAO) Land Cover Classification System (LCCS) and environmental variables (EVs) available within, or accessible from, Geoscience Australia's (GA) Digital Earth Australia (DEA). Classifications representing the LCCS Level 3 taxonomy (8 categories representing semi-(natural) and/or cultivated/managed vegetation or natural or artificial bare or water bodies) were generated for two time periods and across four test sites located in the Australian states of Queensland and New South Wales. This was achieved by progressively and hierarchically combining existing time-static layers relating to (a) the extent of artificial surfaces (urban, water) and agriculture and (b) annual summaries of EVs relating to the extent of vegetation (fractional cover) and water (hydroperiod, intertidal area, mangroves) generated through DEA. More detailed classifications that integrated information on, for example, forest structure (based on vegetation cover (\%) and height (m); time-static for 2009) and hydroperiod (months), were subsequently produced for each time-step. The overall accuracies of the land cover classifications were dependent upon those reported for the individual input layers, with these ranging from $80 \%$ (for cultivated, urban and artificial water) to over $95 \%$ (for hydroperiod and fractional cover). The changes identified include mangrove dieback in the southeastern Gulf of Carpentaria and reduced dam water levels and an associated expansion of vegetation in Lake Ross, Burdekin. The extent of detected changes corresponded with those observed using time-series of RapidEye data (2014 to 2016; for the Gulf of Carpentaria) and Google Earth imagery (2009-2016 for Lake Ross). This use case demonstrates the capacity and a conceptual framework to implement EODESM within DEA and provides countries using the Open Data Cube (ODC) environment with the opportunity to routinely generate land cover maps from Landsat or Sentinel-1/2 data, at least annually, using a consistent and internationally recognised taxonomy.

Keywords: land cover classification; change; Digital Earth Australia; open data cube; Landsat; Australia

\section{Introduction}

To date, there have been few land cover maps that provide consistent coverage for all of Australia. Those that exist have mostly focused on only part of the land cover classification spectrum. For example, the National Vegetation Information System (NVIS; Australian Department of Environment and Energy, 
2017) describes 32 broad categories linked to grasslands, shrublands, woodlands and forests, and natural and artificial bare and water classes. However, as with most Australian land cover mapping systems, NVIS is a combination of inputs from separate mapping efforts by governments at the state and national levels, resulting in an output that has detailed content in some areas but not in others. To create a consistent land cover map for Australia, Geoscience Australia (GA) and the Australian Bureau of Agricultural and Resource Economics and Sciences (ABARES) developed the National Dynamic Land Cover Dataset (DLCD) [1] using data from the Moderate Resolution Imaging Spectroradiometer (MODIS). The DLCD was generated from $250 \mathrm{~m}$ resolution 16-day Enhanced Vegetation Index (EVI) composites, from which 12 coefficients (based on statistical, phenological and seasonal characteristics for each pixel) were clustered using a support vector clustering algorithm. Each class was then labelled using a combination of catchment-scale land-use mapping and the NVIS to provide a consistent land cover map for Australia [2]. However, the $250 \mathrm{~m}$ scale spatial resolution and methodology employed to create DLCD limited its ability to provide high accuracy across its classes and discriminate features at a scale useful for policy and land management.

A number of international projects have classified land cover across Australia according to global taxonomies, including Landcover 2000 and the European Space Agency's (ESA) Climate Change Initiative (CCI) $300 \mathrm{~m}$ resolution land cover product, which employed a subset of the Food and Agriculture Organisation's (FAO) Land Cover Classification System (LCCS), a supervised approach, and temporal information for some biophysical variables (e.g., canopy cover). The value of the FAO LCCS was recognised for Australia by Atyeo and Thackway [3], who stated that this taxonomy provided a comprehensive and flexible system for remapping existing Australian State and Territory vegetation and land cover types and highlighted its potential for providing comprehensive descriptions and maps of land cover for national and international reporting. With the development of Digital Earth Australia (DEA) [4], containing the Australian archive of public good Earth observation (EO) data, such as from the Landsat and Copernicus programs, the LCCS is seen as a candidate to provide ongoing national land cover data for Australia on the DEA platform.

An advantage of the FAO LCCS is that the classes generated closely align with habitat taxonomies that are widely used by ecologists. For example, the taxonomy was adopted within the EU FP7 Biodiversity Multi-Souce Monitoring System (BIO_SOS) [5] project, which applied ecologically-based rules (based on an approach developed for Wales [6] to progressively classify Very High Resolution (VHR) satellite data acquired during pre-flush (e.g., temperate spring or tropical/subtropical dry season) and/or peak flush (e.g., temperate summer or wet season) periods. The BIO_SOS approach followed the LCCS dichotomous hierarchy [6]. During the subsequent FP7 Horizon 2020 Ecopotential Project [7], ecological rules derived from single or dual images were replaced by inputs from a defined set of environmental variables (EVs; e.g., canopy cover, water turbidity) that aligned with those used by the FAO LCCS Version 2 [8]. A diverse and expandable set of additional EVs external to the LCCS (e.g., plant species, woody/herbaceous biomass, sea surface temperature, snow depth) were also integrated. Change events and processes were then identified by accumulating comparisons of LCCS component codes (e.g., for canopy cover) and EVs internal and external to the taxonomy. This led to the establishment of a flexible evidence-based historical and near real-time change alert system. This integrated system of land cover and evidence-based change detection is termed the Earth Observation Data for Ecosystem Monitoring (EODESM) [9].

The EODESM system is currently implemented in Python and makes use of the functionality of the RSGISLib software [10] and KEA file format [11]—specifically, raster attribute tables (RAT). A major advantage of EODESM is that it is applicable to any site worldwide, and it can provide land cover and change classifications at any scale and temporal separation. The system primarily generates land cover and change from available EVs, many of which are obtained from EO data. The approach also focuses on and encourages the standardisation of scientifically robust protocols for recording land cover information and EVs. 


\section{Aims}

The aim of this research was to test the use of EODESM for generating moderate $(\sim 25 \mathrm{~m})$ spatial resolution land cover and evidence-based change maps within the Open Data Cube (ODC) environment and using the framework of Geoscience Australia's (GA) Digital Earth Australia (DEA). Focus was therefore on sites located on the Australian mainland. Specific objectives were to (a) review the nature and current availability of EVs held within or accessible through DEA, their relevance at a national level, the requirements for their translation as inputs for EODESM and any gaps that might exist; and (b) outline an approach for integrating EODESM within the broader ODC environment.

\section{Background to EODESM}

\subsection{Land Cover Classification}

The FAO LCCS Version 2 taxonomy is hierarchical, consisting of a decision tree structure (Figure 1). Each level in the hierarchy consists of one or more binary decisions. The first three levels of the LCCS tree classify, in sequence, vegetated, aquatic, cultivated/managed, urban and artificial water. More detail can then be provided through what is known as the Level 4 classification. These resulting descriptors (such as canopy cover or leaf type) are then combined to produce a cumulated land cover class.

The EODESM system mirrors this hierarchical and modular classification approach by combining products from EO data that (a) assign values of 1 or 0 to Level 1-3 raster inputs and (b) thematic values (e.g., 1, 2 and 3 for water, ice and snow categories, respectively) to layers relevant to the Level 4 hierarchy, with several derived from continuous layers (e.g., water hydroperiod). Additional descriptors external to the LCCS classification (e.g., above ground biomass (AGB)) can also be included. To ensure comparability, scalability and consistency over time, all continuous EVs are accepted only if they can be quantified using pre-defined and recognisable units. Examples include vegetation height $(\mathrm{m})$ and cover $(\%)$, water depth $(\mathrm{m})$ and AGB $\left(\mathrm{Mg} \mathrm{ha}^{-1}\right)$. Thematic layers (e.g., plant species composition) also need to be associated with pre-defined and standardised lists or categories. Indices (e.g., the Normalised Difference Vegetation Index (NDVI)) are avoided within EODESM but are instead used to generate descriptors such as Net Primary Productivity (NPP) or the start of leaf flush (in days) that retain the same meaning (and units) over time. This ensures the longevity of the system, interpretability and objective classification.

\subsection{Change Detection}

To capture the varying nature and rates of change across landscapes, EODESM compares both temporal thematic classifications (e.g., leaf type and water extent) and quantitative (continuous) information on EVs (including those external to the LCCS) retrieved from EO data to build up evidence of changes identified within a defined change taxonomy (e.g., sea level rise, harvesting of crops, wildfires). The same EVs used to generate a land cover classification for a single date or period (e.g., annual; $t_{1}$ ) are generated for a second time step $\left(t_{2}\right)$, and the resulting component codes are compared to determine changes in land cover. The comparison is augmented by comparisons of EVs external to the LCCS. The time interval between $t_{1}$ and $t_{2}$ can vary between days, weeks and months to decades, and land cover and EV comparisons can be undertaken before and after events (e.g., fires, floods) or processes (e.g., regrowth), which can be indicated using more traditional change detection methods such as the Breaks for Additive Season and Trend (BFAST) algorithm [12] or cross correlation analysis [13]. As well as the LCCS classes, the EODESM system also compares an expandable list of EVs that are external to the classification but provide additional descriptors. 


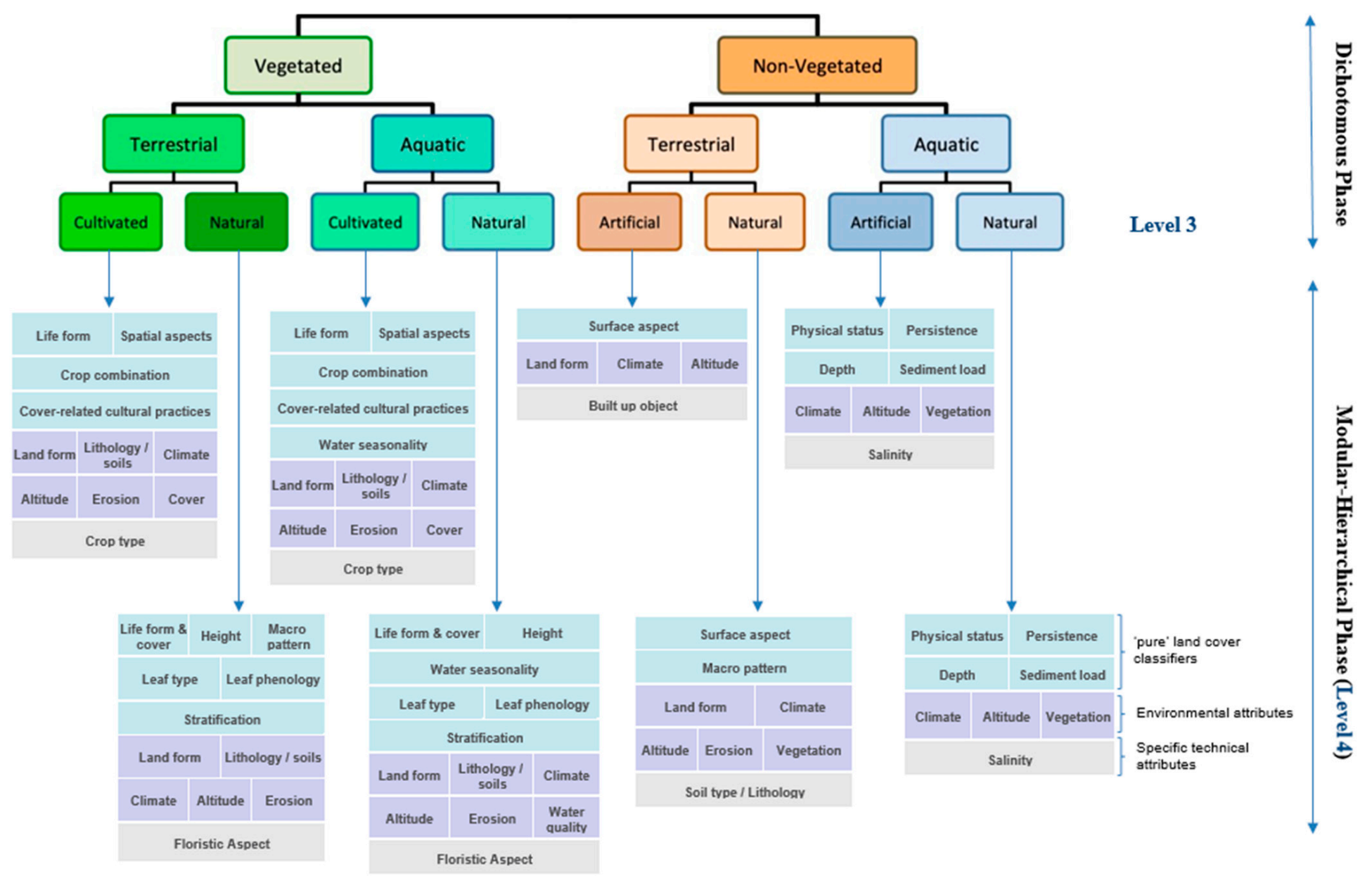

Figure 1. The Food and Agriculture Organisation (FAO) Land Cover Classification System (LCCS) Taxonomy, consisting of the dichotomous and modular-hierarchical phase. 


\section{Study Sites}

The study focused initially on four areas in Queensland and New South Wales (Figure 2). Those in Queensland were the lower Burdekin catchment (coastal semi-natural/natural and agriculture/urban; including the townships of Ayr and Townsville), the Diamantina River (inland riverine natural) and the south eastern Gulf of Carpentaria, including part of the Leichhardt River catchment (coastal dry natural). The Gwydir catchment was selected in New South Wales as it supported inland wetlands and agriculture. These areas collectively were known to experience changes in mangrove extent, hydroperiod and/or agricultural use. Within these, the full range of FAO LCCS Level 3 classes (cultivated or semi-natural, terrestrial or aquatic vegetation, natural and artificial bare surfaces and water) and a diverse range of potential Level 4 classes were present.

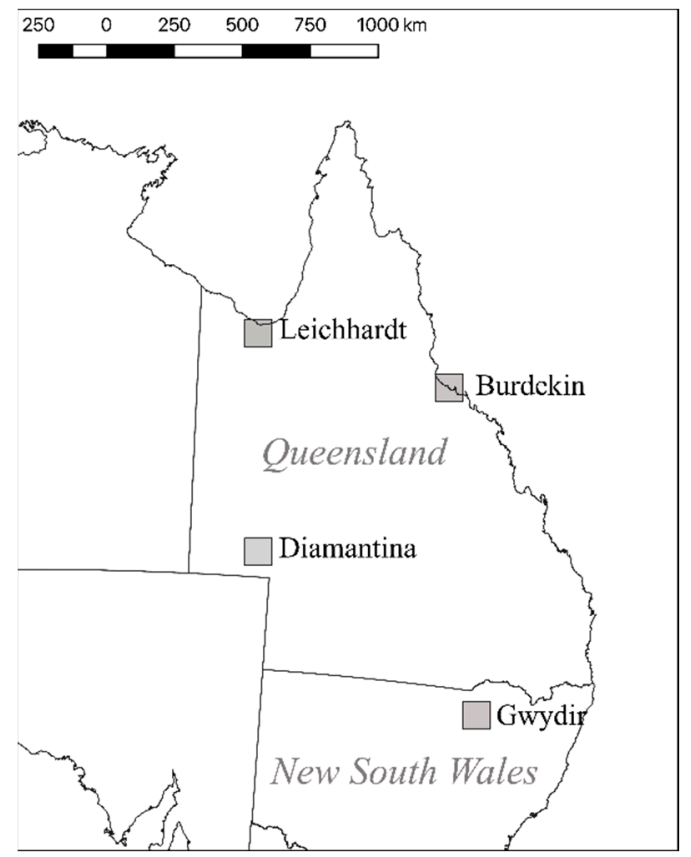

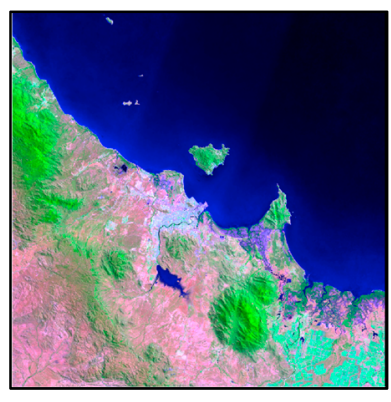

(a)

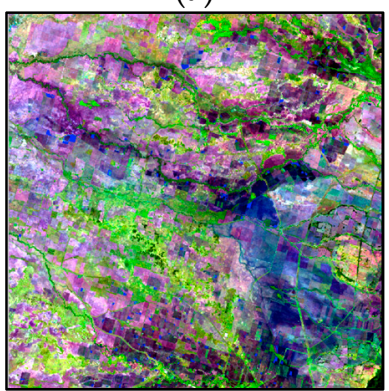

(c)

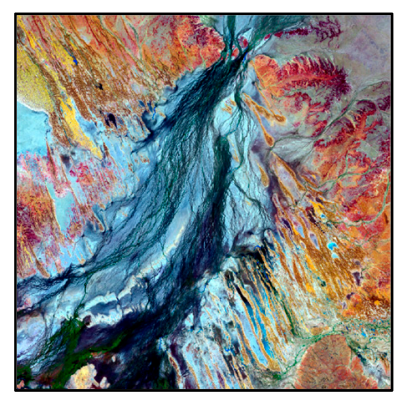

(b)

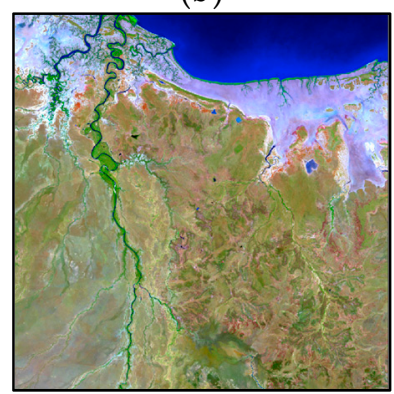

(d)

Figure 2. Landsat annual false colour composites for (a) Ayr (Queensland), (b) Diamantina (Queensland), (c) Gwydir (New South Wales) and (d) the Leichhardt River (northern Queensland).

Initially, focus was on $100 \times 100 \mathrm{~km}$ tiles, with these associated with the spatial storage units used within DEA. However, the classification was extended to several adjoining tiles $(200 \times 200 \mathrm{~km}$ for Leichhardt, with this encompassing the original $100 \times 100 \mathrm{~km}$ area) to demonstrate consistency in classification across a larger region. Higher spatial resolution $(<2-6 \mathrm{~m})$ and temporal change data were available to support the interpretation of the Level 3 change products for the lower Norman River catchment (Leichhardt) and Lake Ross (Townsville, Ayr), and hence these two case study areas were selected to demonstrate the value and potential of the approach. The following subsections provide an overview of the four sites.

\subsection{Lower Burdekin (Townsville and Ayr), Queensland}

Two $100 \times 100 \mathrm{~km}$ tiles centred around the towns of Ayr and Townsville in northern Queensland support a diverse range of cultivated/managed lands with extensive irrigation (primarily for sugar cane). The natural vegetation includes grass, shrub and woodlands. Extensive wetlands (including mangroves and intertidal mudflats) are present along the coast and in some areas inland. Major changes are associated with water inundation, with the hydroperiod varying annually and impacting the dynamics of the wetlands but also controlling the amount of water available for irrigation and general use by the population. Agricultural and urban changes also occur over a range of time steps. 


\subsection{Diamantina, Queensland}

The region is remote and dominated by the Diamantina River, which (because of the flat topography) supports numerous river channels that form a dense interconnected network across the region. Many of the river channels present combinations of herbaceous and woody vegetation, and flooding is highly variable, both intra- and inter-annually. The surrounding landscape is semi-arid with extensive areas of bare ground or sparse vegetation. No cultivated or actively managed areas occur.

\subsection{Gwydir, New South Wales}

The Gwydir River is a perennial river within the Murray Darling River Basin and the catchment is a major agricultural production area. The availability of water has led to the establishment of irrigated agriculture, with particular focus on cotton, although non-irrigation farming also occurs. Within this region, the Gwydir Wetlands support combinations of both herbaceous and woody aquatic vegetation, although much of the non-cultivated area supports dry grass, shrub and woodlands.

\subsection{Southwest Gulf of Carpentaria, Queensland and the Leichhardt River}

The Gulf of Carpentaria is a remote region that supports extensive areas of mud and sandflats, largely because most of the coastal plan is only a few meters above mean sea level and is hence subject to tidal inundation as well as extensive flooding from rivers (particularly the Flinders River). Agricultural areas occupy a very small proportion of the landscape, and the main urban centers are at Karumba and Burketown. The coastline of the Gulf of Carpentaria is macrotidal and supports extensive tracts of mangrove and saltmarsh. However, A substantive dieback of mangroves was experienced in late 2015.

\section{Methods}

\subsection{Available Data}

For the classification of land cover according to the LCCS, a number of EV data layers were available from DEA products (Table 1), whilst others were obtained from other sources but were accessible within the DEA environment (Table 2). All layers listed were available at a $25 \mathrm{~m}$ spatial resolution and provided continental coverage.

\subsection{Input Layers for EODESM}

To support classification within the dichotomous phase (to LCCS Level 3), reference was made to the annual fractional cover layers held within DEA [14]. A threshold of $10 \%$ (i.e., where annual observation summaries were greater than $10 \%$ for the green and non-photosynthetic vegetation fractions) was determined to define vegetated extent (Level 1). The Level 2 aquatic class was generated from a combination of layers with user determined thresholds. The Inter-Tidal Extent model (ITEM) was used to differentiate between non-vegetated intertidal areas such as mud and sand flats. This dataset represents the tidal range of the Australian coastline, generated from the frequency of inundation as quantified from all cloud free Landsat observations of the coastal margin over a 28-year period. Observations were validated with reference to corresponding tide height data at the time of image capture [15]. This study applied ITEM to extract aquatic areas; that is, areas with greater than $10 \%$ and less than $80 \%$ of inundated observations for the Landsat archive. The national (Australian) mangrove maps in [16] were then used to identify areas of tidally inundated areas not captured by ITEM because of the obscuration of water by the mangrove canopies. The Water Observations from Space (WOfS) [17] identified inland and coastal water bodies. An area was considered aquatic when the presence of water detected was greater than $10 \%$ over the annual observations. An ocean mask (defined as water on the seaward margin of the minimum extent of the ITEM intertidal zone) was also added. All four data layers were then used in combination to identify areas associated with the Level 2 aquatic class. To generate the Level 3 classification (8 classes), the Level 1 and Level 2 classes were cross-tabulated 
against data on the extent of agricultural cultivation and artificial land covers, namely urban and water (artificial), with these extracted from the Catchment Scale Land Use of Australia [18] layer. Areas not classified as cultivated or managed were considered to be semi-naturally or naturally vegetated or naturally bare. A summary of the input layers and a description of how these are relevant to EODESM in generating land cover classifications, but also more advanced descriptions (through the inclusion of thematic and continuous EV layers, used internally or external to the LCCS taxonomy), are given in Table 3.

Table 1. Thematic (TM) and continuous (CO) layers from Digital Earth Australia (DEA) products.

\begin{tabular}{cccc}
\hline Data Layer & Type & Derivation & Reference/Source \\
\hline $\begin{array}{c}\text { Fractional cover (photosynthetic and } \\
\text { non-photosynthetic vegetation and bare surface) }\end{array}$ & CO & Spectral unmixing & Gill et al. (2018) [14] \\
\hline Water Observations from Space (WOfS) & CO & Classification & Mueller et al. (2016) [17] \\
\hline Inter-Tidal Extent model (ITEM) & TM & Classification & Sagar et al. (2017) [15] \\
\hline National Mangroves & TM & Classification & Lymburner et al. (2018) [16] \\
\hline
\end{tabular}

Table 2. Thematic (TM) and continuous (CO) layers currently external to DEA.

\begin{tabular}{cccc}
\hline Data Layer & Type & Derivation & Reference/Source \\
\hline $\begin{array}{c}\text { TERN Continental } \\
\text { Vegetation Height (CVH) }\end{array}$ & CO & $\begin{array}{c}\text { Generated through integration } \\
\text { of LiDAR, L-band SAR and } \\
\text { Landsat }\end{array}$ & Scarth et al. (2019) [19] \\
\hline $\begin{array}{c}\text { National Vegetation } \\
\text { Information System (NVIS) }\end{array}$ & C) & $\begin{array}{c}\text { Collation of State and Territory } \\
\text { vegetation maps }\end{array}$ & $\begin{array}{c}\text { Australian Department of the } \\
\text { Environment and Energy DOEE [20] }\end{array}$ \\
\hline $\begin{array}{c}\text { Catchment Scale Land Use } \\
\text { of Australia }\end{array}$ & TM & $\begin{array}{c}\text { Cultivated areas from } \\
\text { cadastral information }\end{array}$ & $\begin{array}{c}\text { Australian Bureau of Agricultural and } \\
\text { Resource Economics and Sciences } \\
\text { ABARES (2016) [18] }\end{array}$ \\
\hline $\begin{array}{c}\text { Australian Hydrological } \\
\text { Geospatial Fabric } \\
\text { (Geofabric) }\end{array}$ & TM & $\begin{array}{c}\text { Buildings and infrastructure } \\
\text { from cadastral information }\end{array}$ & Artificial water (dams and \\
reservoirs) & Bureau of Meteorology \\
\hline
\end{tabular}

Table 3. Use of different inputs to the Earth Observation Data for Ecosystem Monitoring (EODESM).

\begin{tabular}{cccc}
\hline Input Layers & Level 3 & Level 4 & EVs \\
\hline Fractional Cover & Vegetated & Canopy cover & Canopy cover (\%) \\
WOfS & Aquatic & Hydroperiod & Hydroperiod (days) \\
ITEM & Aquatic/bare ${ }^{2}$ & Tidal extent & Relative tidal inundation frequency \\
GMW Mangroves & Aquatic & Tidal extent & \\
TERN CVH & & Lifeform, vegetation (canopy) height & Canopy height $(\mathrm{m})$ \\
NVIS & & & Dominant genus \\
ABARE & Cultivated & Field size & Field size (ha) Crop type \\
& Urban & Density, geometry & Area (\%) \\
& Artificial water & Water depth & Water depth (m) \\
\hline & ${ }^{1}$ Classification at Level 3 depends upon the date or period of observation.
\end{tabular}

In the modular-hierarchical Phase (LCCS Level 4), more detailed descriptions of the LCCS Level 3 vegetated category were obtained by again referencing the Landsat-derived fractional cover (indicating canopy cover percentage) and canopy height in meters [19], with the latter generated using a combination of Advanced Land Observing Satellite (ALOS) Phased Arrayed L-band Synthetic Aperture Radar (PALSAR) and Landsat sensor data acquired in 2009. Woody vegetation was then associated with objects for which the average canopy height and cover exceeded $2 \mathrm{~m}$ and $20 \%$, respectively, with trees and shrubs distinguished as being $\geq 5 \mathrm{~m}$ and $<5 \mathrm{~m}$, respectively. All forests 
were assumed to be evergreen (as is typical in Australia). NVIS data can also be used to broadly discriminate those dominated by broadleaved (primarily Eucalyptus and Acacia) and needle-leaved types (e.g., primarily Callitris and Casuarina species). The areas defined as aquatic were then further described using WOfS according to the hydroperiod classes defined within LCCS Level 4, namely 1-3, 4-6, 7-9 and >9 months. ABARES data can also be used to indicate field size and crop type and metrics describing urban areas.

For all four areas, a comparison of the LCCS land cover classifications was undertaken between 2009 (associated with the structural classification of Scarth et al. [19]) and 2016 (the latest year, at the time of study, with coverages for all DEA layers) to assess the potential of EODESM for detecting change in EVs (namely hydroperiod and canopy cover). However, for the Gulf of Carpentaria, including the Leichardt River, comparisons were made between 2014 and 2016 as a substantive dieback of mangroves was observed from late 2015 [22].

\subsection{Implementation of the Land Cover Classification}

The overall mechanism for applying the classification was based on the system outlined in Clewley et al. [23] using Python to combine functionality from a number of different packages, primarily RSGISLib [10], and using the KEA file format [11] for data storage.

\subsubsection{Segmentation}

For each area, objects were generated by applying the algorithm of Shepherd et al. [24] (available within RSGISLib) to annual (geomedian; [25]) composites (for 2016) of multi-spectral Landsat sensor data and for each tile through DEA. Once proven at the object level, the analysis was applied at a per-pixel level to take advantage of the full resolution of the data.

\subsubsection{Classification}

The classification procedure applied rules to each environmental dataset and for each time period (i.e., $t_{1}$ and $t_{2}$ ). For both periods, and to generate the Level 3 classes, each object (which can be a segment or pixel) was populated with a value of 1 or 0 , respectively, to indicate the presence or absence of the feature in question (i.e., vegetation, aquatic environments, cultivation and artificial surfaces or water). The values for each were then cross-tabulated to assign each object to the appropriate LCCS Level 3 category (e.g., vegetated aquatic cultivated). Once the classification system progressed to the more detailed modular levels of LCCS in Level 4, values were assigned separately on the basis of the numerical values associated with each LCCS code specific to each modular layer. For example, leaf types are assigned to broadleaved (D1), needle-leaved (D2) and aphyllous (D3) in the FAO LCCS taxonomy, and the raster layer is accordingly given values of 1,2 and 3. In the case of hydroperiod, canopy cover and canopy height, the continuous layers were converted to codes according to the LCCS-2 classification scheme, with each category assigned a value associated with specific LCCS codes (e.g., perennial water (7-9 months) was assigned a value of 7 representing the code B7).

As well as the component codes, the original numeric values derived from the EVs (e.g., canopy height) for each object were integrated within the Raster Attribute Table (RAT), as was additional information external to the classification (e.g., NVIS dominant species type, as a numeric code value). Once all layers were integrated and RAT columns populated, the component codes were combined to produce the final combined string prior to translation to a meaningful Level 4 class name. Standardised colour schemes developed by Lucas and Mitchell [8] for the Level 3 and Level 4 classifications were then applied.

\subsubsection{Evidence-Based Change Detection}

To demonstrate the capacity of EODESM to generate descriptions of land cover change alerts, two of the four test sites were chosen (the lower Norman River catchment near Karumba in Queensland 
and within the Leichhardt River scene) and Lake Ross (within the Townsville-Ayr scene), given the availability of suitable field and/or higher resolution EO data for validation (Figure 3).

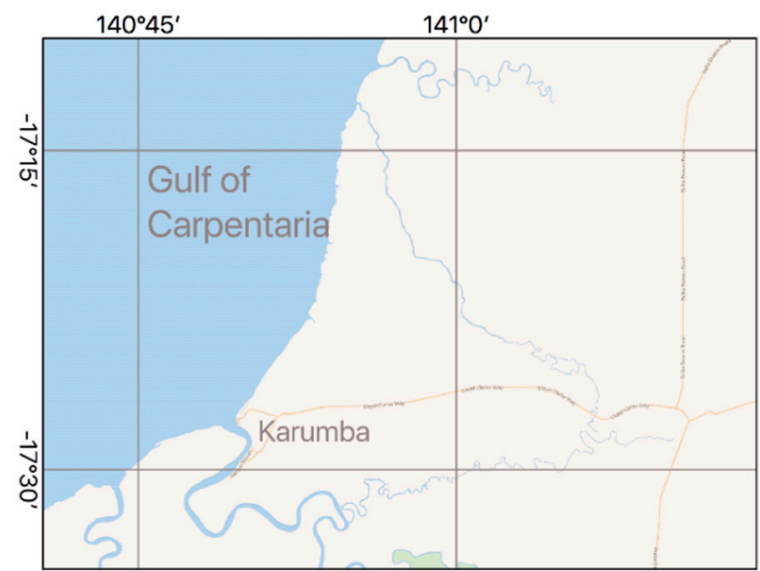

(a)

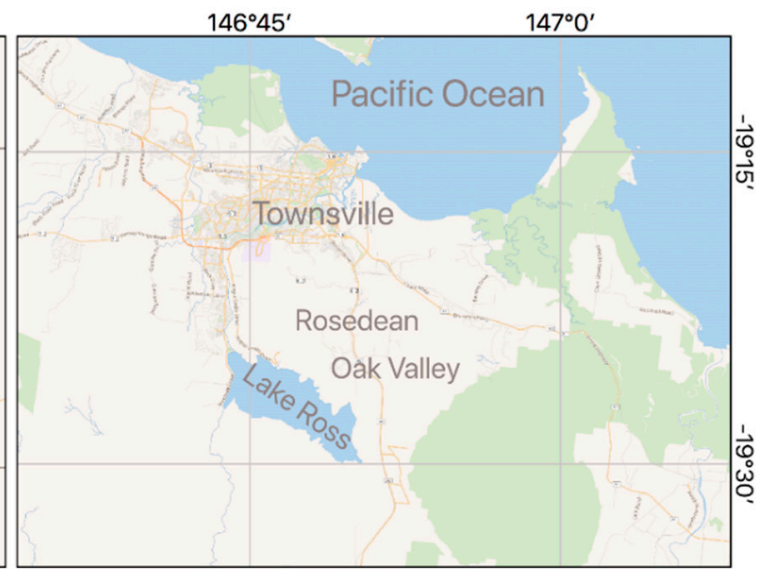

(b)

Figure 3. Location maps for detailed assessment of changes in (a) mangroves on the coastal margin near Karumba, Gulf of Carpentaria between 2014 and 2016 and (b) water extent in Lake Ross, Burdekin Catchment, near Townsville between 2009 and 2016.

In late 2015, a substantive dieback of mangroves occurred along the coastline of the Gulf of Carpentaria, with this attributed to a combination of a substantive drop $(20-30 \mathrm{~cm})$ in sea level, high temperatures and low rainfall [22]. The dieback was most rapid and noticeable within mangrove communities dominated by lower stature species (e.g., dominated by Avicennia marina) on the landward margin, but there was some evidence of dieback several years earlier (2012) within mangroves dominated by Rhizophora stylosa on the landward margin. Airborne and field observations in dieback areas $[26,27]$ indicated that the dieback in mangroves did not immediately result in a loss of mangrove extent nor a change in canopy height but rather a change in canopy cover. Hence, attention focused on establishing changes in the Level 3 classes but also Level 4 canopy cover between 2014 and 2016, with these representing the pre-dieback and post-dieback periods. Comparisons were made against time-series of RapidEye data and the derived Normalised Difference Vegetation Index (NDVI) data provided by Planet [28] for 2014 and 2016. Changes in the WOfS hydroperiod product were also noted in the lower catchment of the Leichhardt River. For Lake Ross, a progressive loss of water area was noted between 2014 and 2016 within the WOfS product. Reservoir volume data (percentage of maximum capacity), Google Earth Imagery (GEI) and RapidEye data were available for the validation of these changes.

\section{Results}

\subsection{Land Cover Classifications}

The EODESM land cover classification procedure was applied to the four study areas, for time periods $t_{1}$ and $t_{2}$, with these being 2009 and 2016, respectively, for Townsville-Ayr, Diamantina and Gwydir and 2014 to 2016 for the Leichhardt. The latter time interval was selected to capture the mangrove dieback event. Level 3 and 4 outputs for 2016 are shown in Figures 4 and 5, respectively, with the latter showing an extended area of $200 \times 200 \mathrm{~km}$ (for Leichhardt) for the Level 4 classification.

Each map was generated from objects (segments as a first test and then pixels as a final product) that were populated with LCCS components and combined codes and then translated to a full taxonomic description plus thematic and continuous EVs (e.g., \% canopy cover or hydroperiod in days). The set of descriptive attributes to complement the classification were also retained within the RAT row for each object. The legend for the classifications was built from the available layers and provided a comprehensive description of land cover classes. 


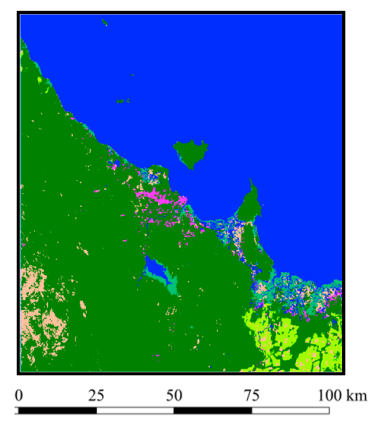

(a)

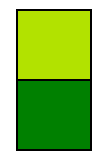

Cultivated terrestrial vegetated (CTV) Natural terrestrial vegetated (NTV)

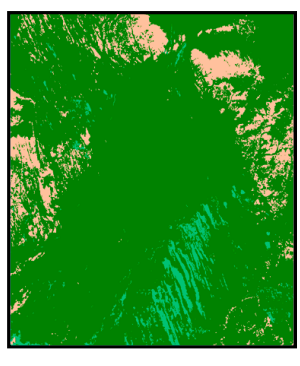

(b)

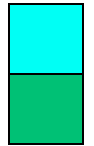

Cultivated aquatic vegetated (CAV) Natural aquatic vegetated (NAV)

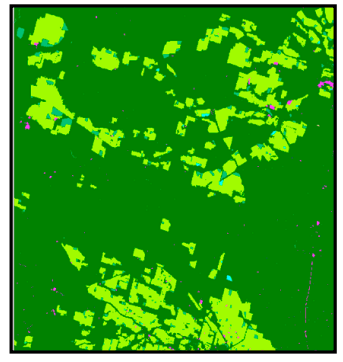

(c)

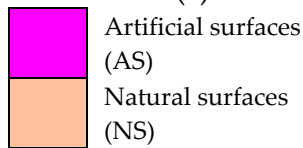

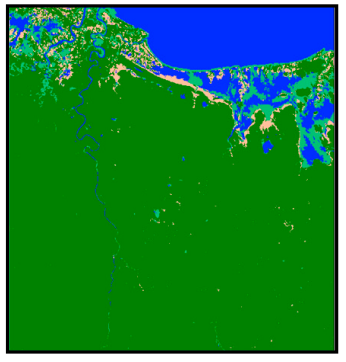

(d)

Figure 4. Land cover classifications for (a) Ayr (Queensland), (b) Diamantina (Queensland), (c) Gwydir (New South Wales) and (d) the Leichhardt River (northern Queensland) according to the LCCS-3 taxonomy. Each area represents $100 \times 100 \mathrm{~km}$. Acronyms are also provided.

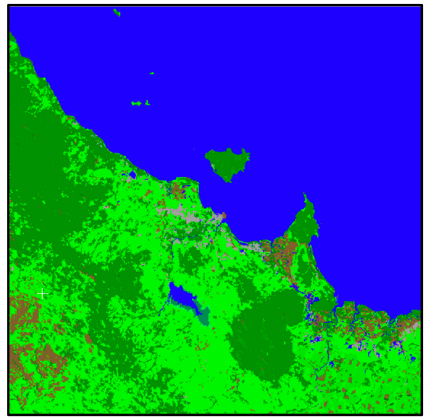

(a)

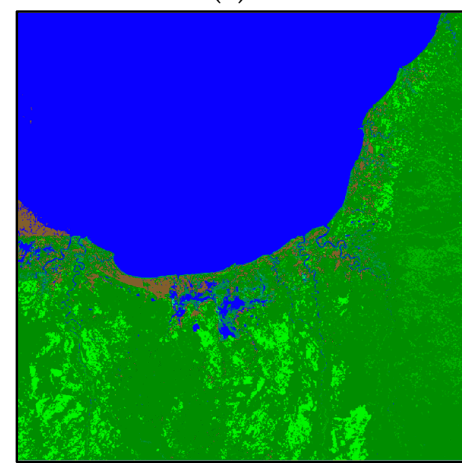

(d)

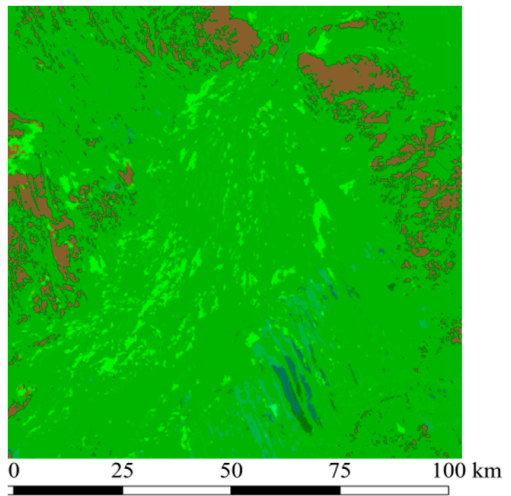

(b)

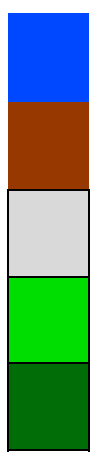

Water 1

Lifeform ${ }^{2}$

Bare

Urban

Shrub crops ${ }^{5}$ Canopy

Cover ${ }^{3}$

Herbaceous crops ${ }^{5}$

${ }^{1}$ Water areas include hydroperiod classes (> 9 months (B1), 7-9 months (B7), 4-6 months (B8) and 1-3 months (B9)).

${ }^{2}$ Lifeform classes of herbaceous (graminoids and/or forbs (A2), trees (A3) and shrubs (A4)).

${ }^{3}$ Canopy cover classes of sparse (1 to $10-20 \%$; A14), open (10-20 to 60-70\%; A11) and closed (> 60-70\%; A10) for both aquatic and terrestrial vegetation.

${ }^{4}$ Canopy height classes of 3-7 m (B7), 7-14 m (B6) and > $14 \mathrm{~m}$ (B5) for both aquatic and terrestrial vegetation.

${ }^{5}$ Gwydir only.

Figure 5. Land cover classifications for (a) Ayr (Queensland), (b) the Diamantina River (Queensland), (c) Gwydir catchment (New South Wales) and (d) the Leichhardt River (northern Queensland; $200 \times 200 \mathrm{~km}$ ) according to the LCCS-4 taxonomy. 
The accuracy of the land cover classifications is dependent upon that of the input layers used for their generation and, where available, these are listed in Table 4 . Those reported for the individual input layers ranged from between $80 \%$ (for cultivated, urban and artificial) to over $95 \%$ (for hydroperiod and fractional cover). A current limitation is that these accuracies are reported using different mechanisms, and hence a future challenge will be to develop an effective approach for standardizing and combining these within a common framework.

Table 4. Reported accuracies of the EV layers used as input to EODESM.

\begin{tabular}{|c|c|c|}
\hline EV & Derived Layer & Validation \\
\hline Fractional Cover & Vegetated & $\begin{array}{c}\text { The fractional cover product has an overall RMSE of } 11.8 \% \text {. } \\
\text { The error margins for photosynthetic vegetation, } \\
\text { non-photosynthetic vegetation and bare soil fractions are } \\
11.0 \%, 17.4 \% \text { and } 12.5 \% \text {, respectively [14]. }\end{array}$ \\
\hline WOfS & Aquatic & $\begin{array}{l}\text { Based on } 3.4 \text { million validation points; overall accuracy of } 97 \% \text {; } \\
\text { with water identified } 93 \% \text { of time. }\end{array}$ \\
\hline ITEM & Aquatic/Bare & $\begin{array}{l}\text { Mean absolute height difference between (non-inundated) } \\
\text { estimated and actual surface elevation of } 0.57 \mathrm{~m} \text { at the } \\
\text { continental level. Based on Real Time Kinematic (RTK) Global } \\
\text { Positioning Systems (GPS) ground data, with this being } \\
\text { indicative of tidal water depth. }\end{array}$ \\
\hline GMW Mangroves & Aquatic/Vegetated ${ }^{1}$ & $\begin{array}{l}\text { Users' and producers' accuracies from } 92-93 \text { and } 97-99 \% \text {, } \\
\text { respectively [16]. }\end{array}$ \\
\hline TERN CVH & & $\begin{array}{l}\text { Close correspondence with airborne LIDAR profiles from } \\
\text { TERN sites [19]. }\end{array}$ \\
\hline NVIS & Dominant species ${ }^{2}$ & $\begin{array}{c}\text { Final accuracy of } 85 \% \text { in the delineation of vegetation map } \\
\text { units based on aerial photography at } 1: 20,000 \text {. }\end{array}$ \\
\hline \multirow[t]{3}{*}{ ABARE $^{3}$} & Cultivated & $\begin{array}{l}\text { Composite product generated from State and Territory land } \\
\text { cover maps with stated overall accuracies above } 80 \% \text { at the } \\
\text { catchment scale. }\end{array}$ \\
\hline & Urban & As above \\
\hline & Artificial water & As above \\
\hline
\end{tabular}

${ }^{1}$ Generated through GMW. ${ }^{2}$ Undertaken by experienced interpreters (final accuracy of $85 \%$ ). ${ }^{3}$ Australian Bureau of Agricultural and Resource Economics and Sciences (2011), guidelines for land-use mapping in Australia: principles, procedures and definitions, fourth edition, Australian Bureau of Agricultural and Resource Economics and Sciences, Canberra.

\subsection{Land Cover Change Maps}

By comparing the FAO LCCS component codes between $t_{1}$ and $t_{2}$, maps of changes in Level 3 categories were obtained for all four sites (Figure 6). Between-class changes in Level 3 categories from $t_{1}$ and $t_{2}$ can indicate multiple transitions (e.g., bare ground to terrestrial vegetation, natural water to artificial cultivated vegetation or vice versa) or relative stability in the landscape (e.g., water stays as water). Where major transitions occur at Level 3, the Level 4 classifications can provide more detailed information just before and immediately following the transitions. Where the Level 3 class between $t_{1}$ and $t_{2}$ does not change, a comparison of the Level 4 classifications provides insights into within-class changes, such as the annual hydroperiod (e.g., from 1-3 months to 4-6 months) or fractional vegetation cover (percentage change). Within EODESM, changes can be represented at both levels, with this indicated in Figure 7, whereby both changes between LCCS Level 3 categories and within Level 4 (hydroperiod) are overlain on the $t_{2}$ Level 4 classification. Multiple layers of change (annual, monthly or daily) can also be viewed simultaneously and for different change groups (e.g., canopy cover as well as hydroperiod). 


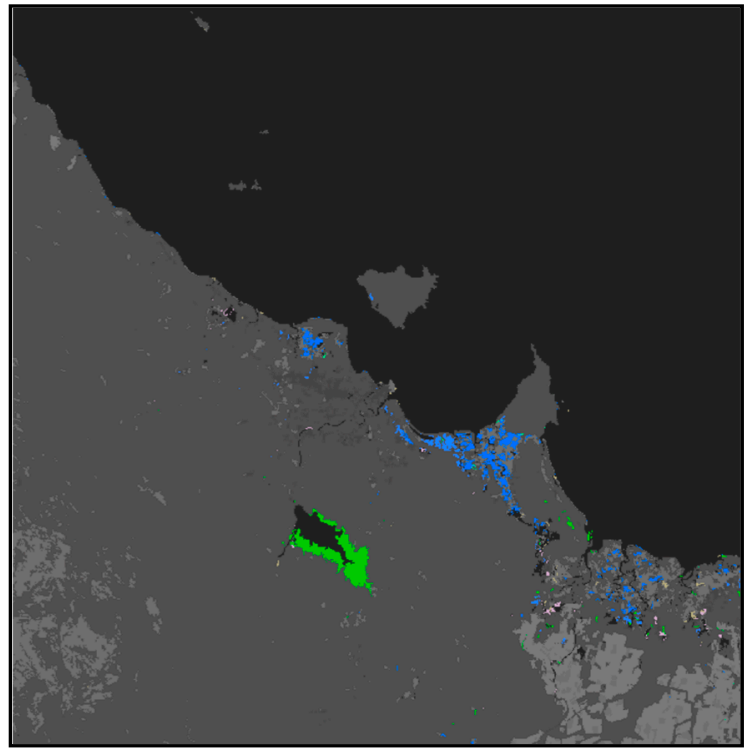

(a)

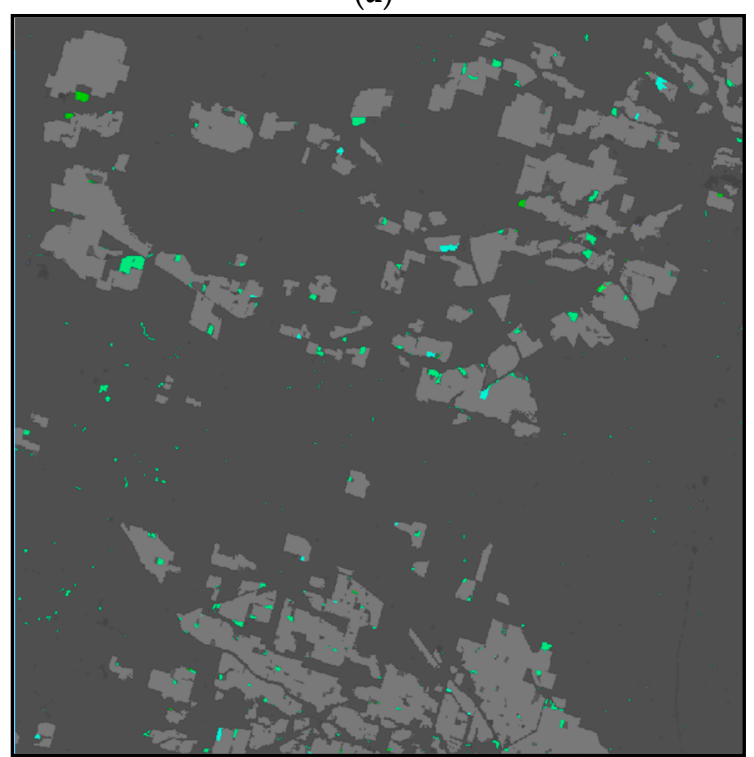

(c)

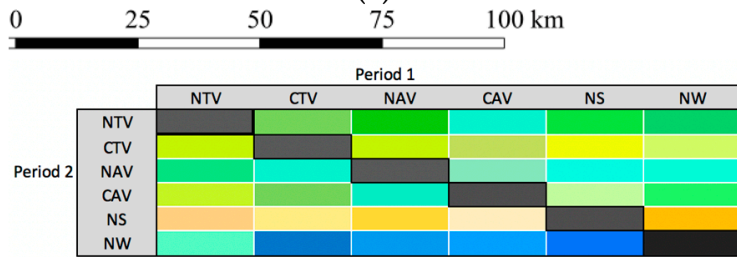

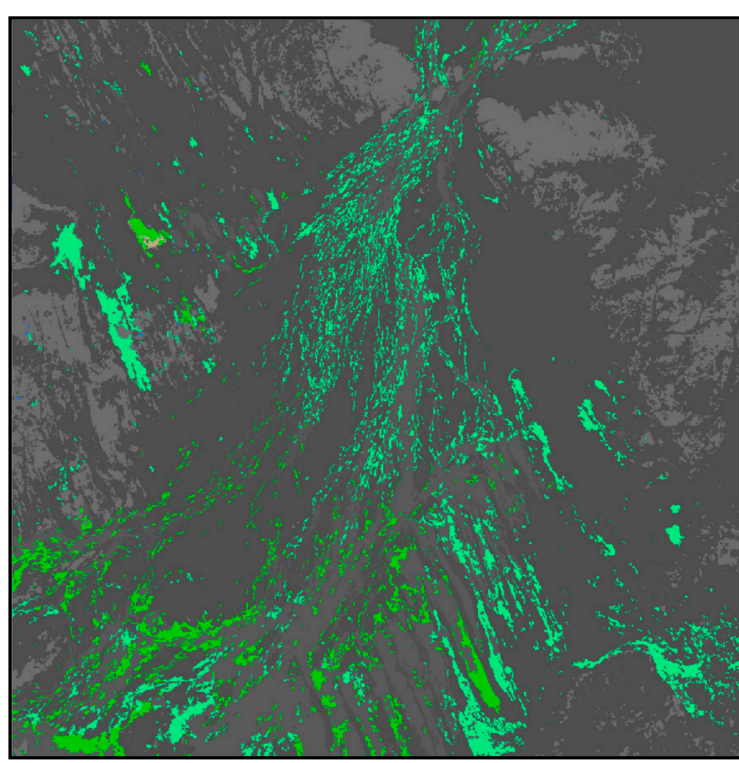

(b)

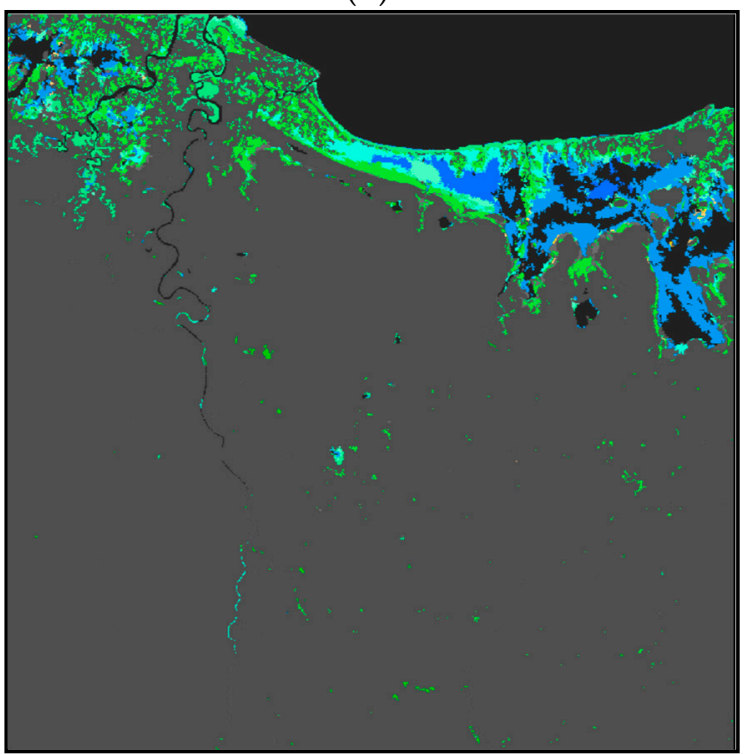

(d)

Figure 6. Land cover (LCCS Level 3) change maps for (a) Ayr (Queensland), (b) Diamantina (Queensland), (c) Gwydir (New South Wales) and (d) the Leichhardt River (northern Queensland) according to the LCCS-3 taxonomy. The dominant transition is from natural bare surfaces (NS) and natural aquatic vegetation (NAV) to natural water (NW). 

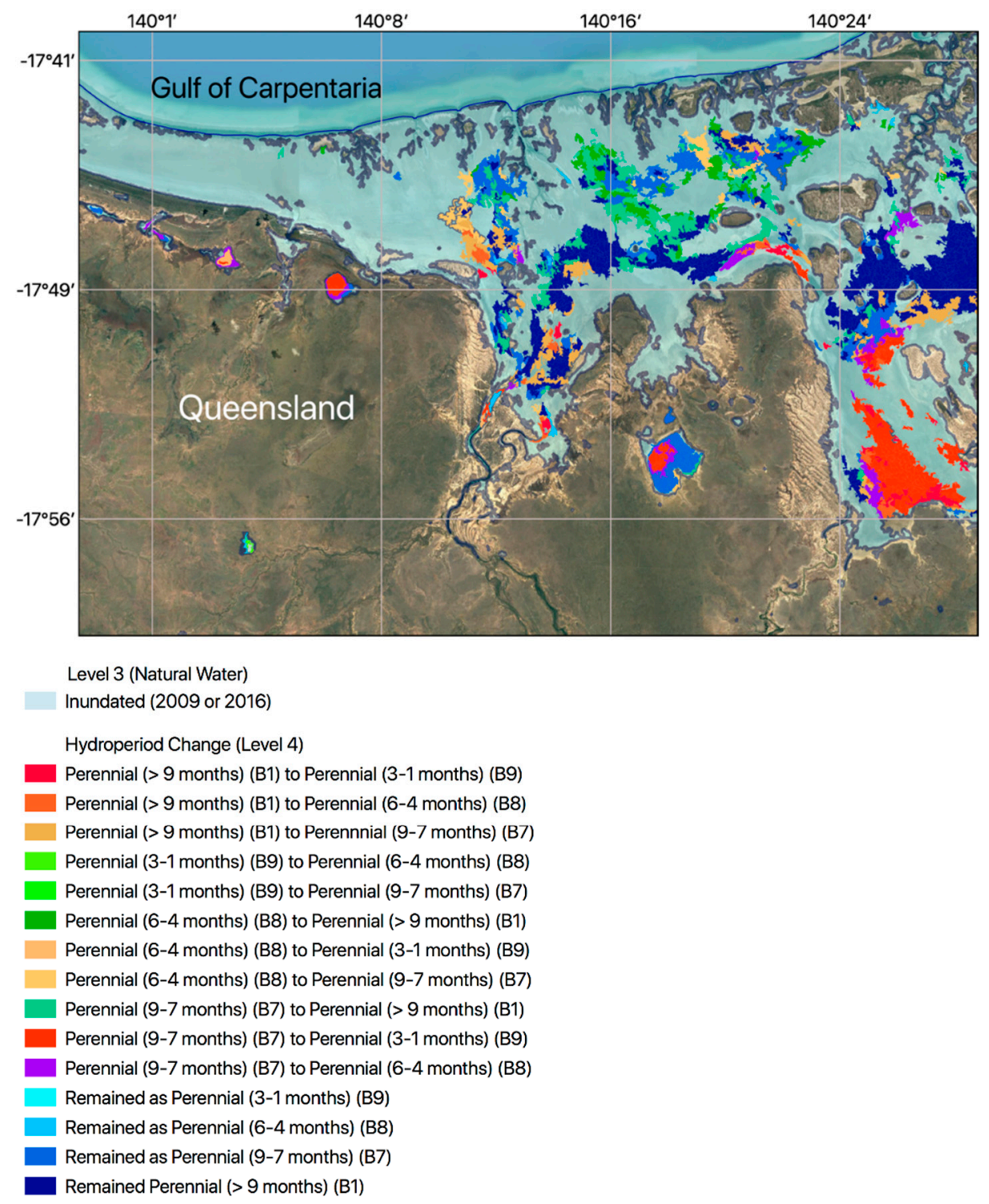

Figure 7. Classification of LCCS Level 4 transitions (in hydroperiod) between $t_{1}$ and $t_{2}$ for the Leichhardt area $(100 \times 100 \mathrm{~km})$ and only for areas where the LCCS Level 3 classes remained stable. Hydroperiod classes are $>9$ months (B1), 7-9 months (B7), 4-6 months (B8) and 1-3 months (B9). The total area that was inundated in either 2009 or 2016 is indicated.

\subsection{Evidence-Based Change Descriptions}

A fuller description of changes between $t_{1}$ and $t_{2}$ was demonstrated by combining transitions in the two taxonomic levels for the lower Norman River catchment (Leichhardt) and Lake Ross (Townsville, Ayr). In both cases, the LCCS component codes (for Levels 3 and 4) and the original thematic and continuous information for each LCCS input variable were maintained in the RAT and, when used in combination, allowed changes to be detected and described on the basis of evidence.

In the lower Norman River, the dieback of mangroves between 2014 and 2016 was identified by a rapid decline in the Landsat-derived Normalised Difference Vegetation Index (NDVI) from values typically exceeding 0.6 to those that were $<0.1$ (Figure 8a). This decline was captured by a Level 3 change from natural aquatic vegetation (i.e., mangroves) to natural water but also a loss of canopy cover (typically from $70-100 \%$ ), as determined by comparisons of the Landsat-derived fractional (green) cover and derived Level 4 component codes for canopy cover between these periods (Figure 8b). Whilst time-series data on canopy height were not available, as the height layer of Scarth et al. [19] 
was generated for 2009, airborne LIDAR data were acquired in 2016, with these indicating degraded forests with loss of structural integrity. The change classification indicated a close correspondence with the area of dieback observed within mangroves (which had been mapped previously by applying a random forest classifier to 2014 Rapideye spectral data-Figure 8c-and quantified by comparing time-series of RapidEye NDVI data from 2014 and 2016-Figure 8d)).

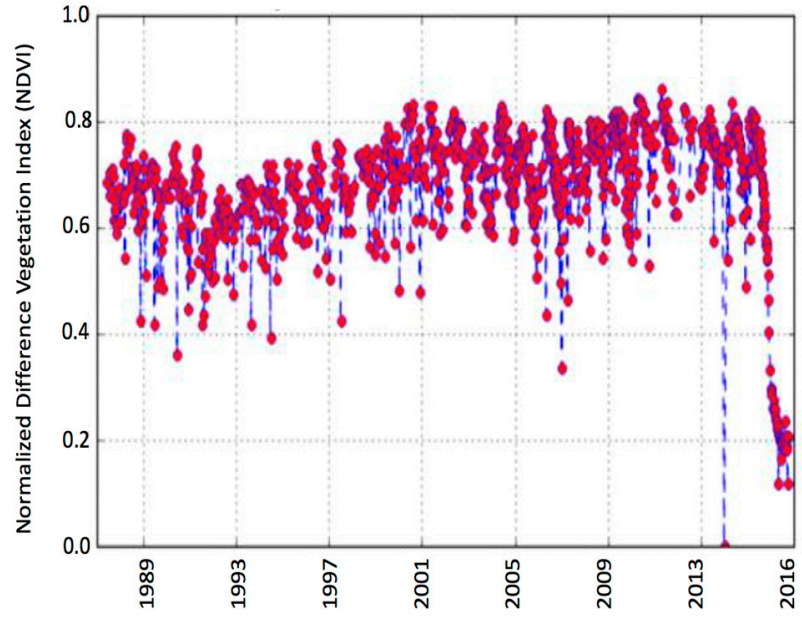

(a)
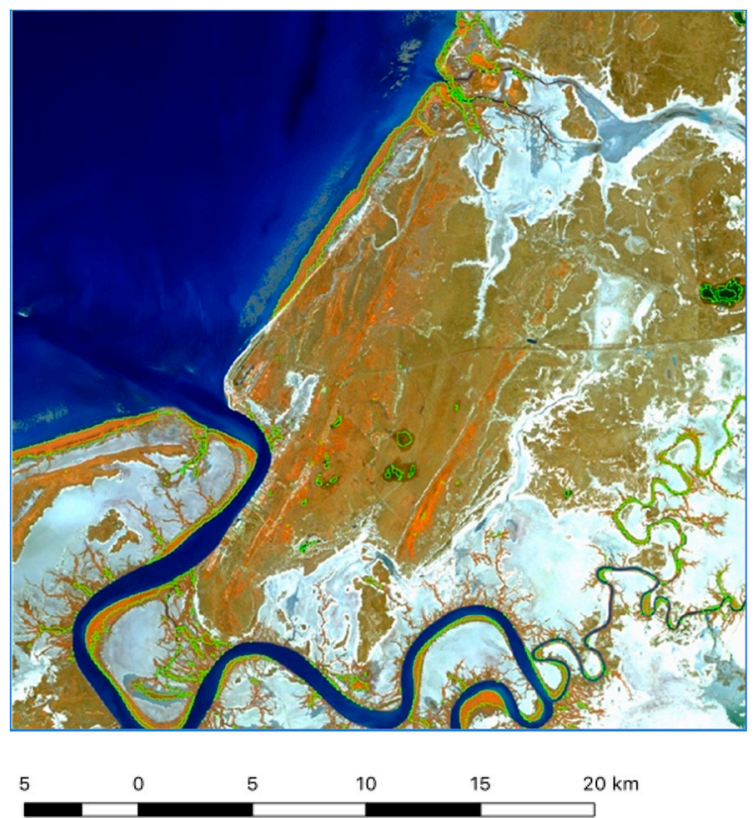

(c)

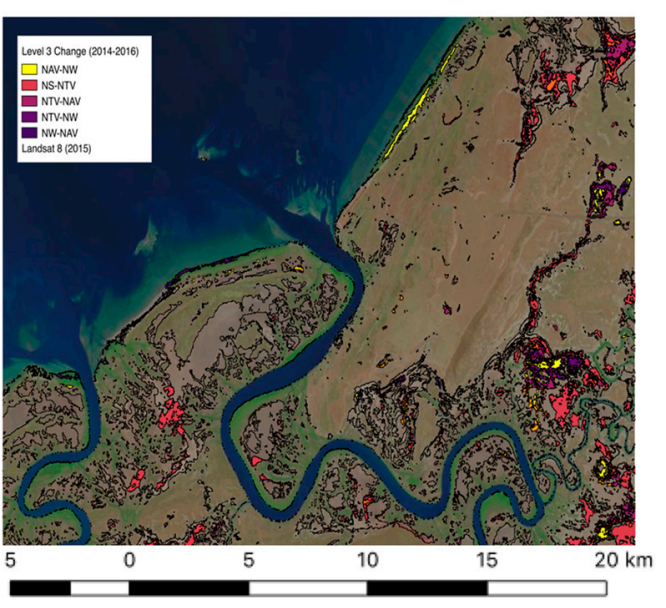

(b)

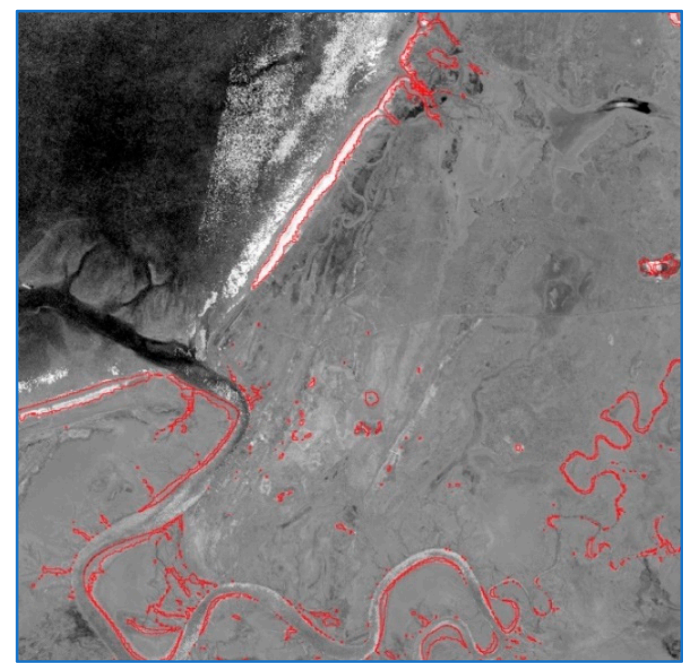

(d)

Figure 8. (a) Time-series of Landsat-derived Normalised Difference Vegetation Index (NDVI) data extracted from DEA, indicating declines between 2014 and 2016 associated with mangrove dieback along the Gulf of Carpentaria. (b) Changes in land cover detected based on a transition between the Level 3 classes, including mangrove dieback (from natural aquatic vegetation to natural water; NAV to NW). Other changes, including flooding of natural terrestrial vegetation (NTV) and vegetation encroachment onto previously naturally bare surfaces (NS), are also indicated. (c) RapidEye image from 2014 showing the extent of mangroves (green line) as mapped using a random forest classifier and (d) differences in the RapidEye-derived NDVI between 2014 and 2016 showing the extent of mangrove dieback (decreases indicated in white; mangrove area classified in 2014 overlain in red). 
The change detection example over the Townsville-Ayr study area indicated that, between 2014 and 2016, the area experienced a change in hydroperiod and a subsequent decrease of water within Lake Ross. This decrease was accompanied by an increase in aquatic vegetation, with this restricting the area of open water. The evidence for this change was based on a change in the LCCS Level 3 category from artificial water to vegetated aquatic (semi) natural indicated by a change in fractional cover from $0 \%$ (as a water class) to over $80 \%$ vegetated (Figure 9 a). The change indicated herbaceous vegetation instead of open water, providing evidence of falling water levels within the dam. This was attributed to low rainfall during this period and water extraction for use by population and irrigated agriculture in proximal areas. This change was also observed within RapidEye data (Figure 9b) and agreed with records of water extent produced by Townsville County Council (Figure 9c). Over this period, dam levels have decreased progressively to a minimum (in 2016).

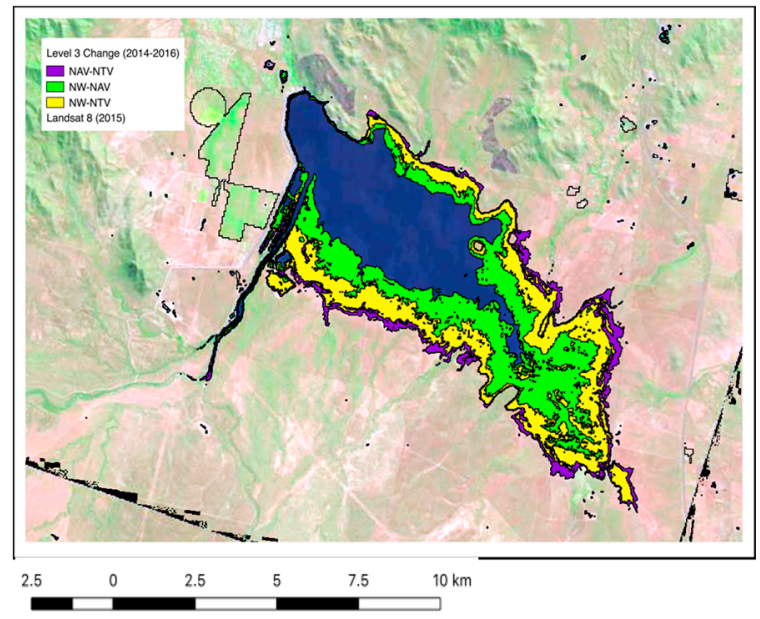

(a)

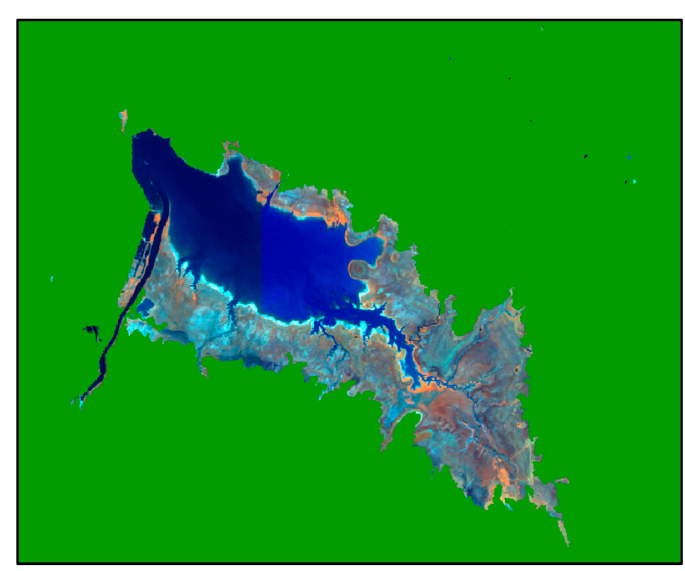

(b)

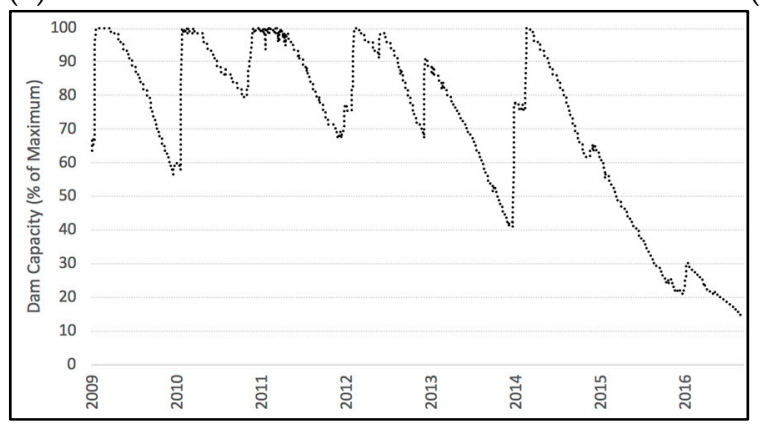

(c)

Figure 9. (a) Transitions between the Level 3 classes of natural aquatic vegetation (NAV), natural terrestrial vegetation (NTV) and natural water (NW) for Lake Ross between 2014 and 2016. Such changes were associated with a progressive decrease in hydroperiod between 2009 and 2016 and an associated increase in the extent of both aquatic and terrestrial vegetation. (b) RapidEye image (near infrared (NIR), red edge and red in RGB) from 2016 highlighting the reduced extent of water and replacement by aquatic and terrestrial vegetation. (c) Changes in dam capacity (\%) between 2009 and 2016.

For Lake Ross (Burdekin catchment), the Landsat sensor imagery within the Google Earth Engine (GEE; Figure 10) further confirmed the progressive loss of open water, the retreat of aquatic (wet) vegetation and a transition to drier vegetation on the outer margins of the lake's basin. A confusion matrix was difficult to generate because of the lack of a field survey at the time of the image acquisitions, with this highlighting the requirement for the near real-time measurement of equivalent land covers. 


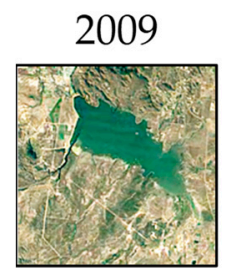

2013
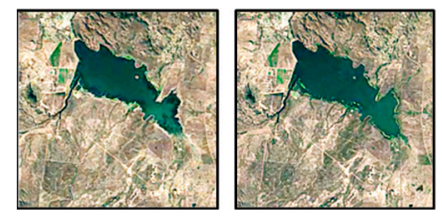

(a)

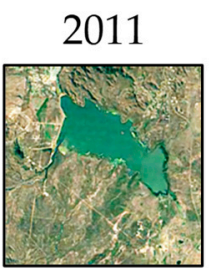

2015

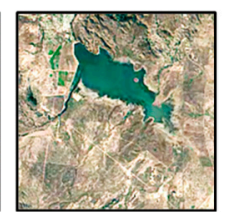

(a)
2012

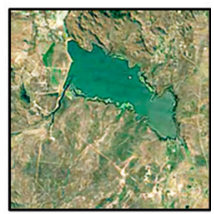

2016
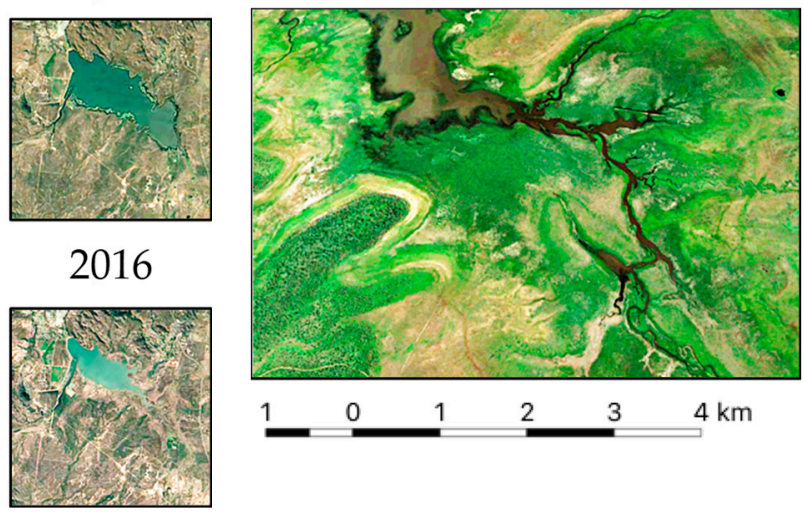

(b)

Figure 10. (a) Decrease in the extent of water in Lake Ross near Townsville, Queensland, between 2009 and 2016 and the associated increase in aquatic vegetation, as observed within Google Earth Engine. (b) The distribution of aquatic (wet; primarily green) and drier (brown) vegetation in the high-resolution Google Image of 2016 (southeast section).

\section{Discussion}

\subsection{Overview of Approach}

The classifications of land cover according to the FAO LCCS were generated from multiple thematic and continuous EV layers, published within or accessible by DEA. Whilst the focus initially was on several $100 \times 100 \mathrm{~km}$ areas relating to the four sites, all data layers used were also available at a national level, with this indicating the capacity for generating similar classifications across Australia for different points in time through DEA. All of the input layers were also associated with unit measures (e.g., m, \%, number of days) or pre-defined thematic categories (e.g., numeric codes representing urban, cultivated areas, dominant genus). All data were provided at a $25 \mathrm{~m}$ spatial resolution, which provided a consistent resolution and spatial reference for comparison. The initial testing was undertaken using segments but then focused at the pixel level to allow the capture of greater detail within the landscape.

In this study, attention was focused on the use of annual summaries of EVs (including fractional cover and persistent green fraction), with these providing a consistent time reference for comparison and a basis for linking concurrent or dependent changes between EVs. Several, but all, datasets were also associated with assessments of retrieval accuracy. Some datasets were only available for one point in time (e.g., a specific year, as in the case of the ABARES layers and also the TERN CVH. Whilst these can be construed as limiting, the current implementation of EODESM highlighted the need for the more regular production of input datasets. For example, the production of annual vegetation CVHs would provide significant support for the mapping of vegetation change, particularly when integrated with canopy cover. This could be achieved by using, for example, the Global Ecosystem Dynamics Investigation (GEDI) LiDAR or interferometric SAR (Tandem-X) data. Algorithms for routinely retrieving these parameters across Australia could also be developed or improved. A limitation of the current CVH layer was that heights were assigned to segments [19], and so the area and outline of the segments was evident within the classification of vegetated categories at LCCS Level 4.

The EODESM system compares input layers from $t_{1}$ and $t_{2}$, and this comparison aligns well with annual change assessments. The time between $t_{1}$ and $t_{2}$ can, however, be varied, allowing the comparison of images acquired from consecutive image overpasses (e.g., daily, weekly, monthly) as well as inter-annual and even decadal periods (based on derived summaries). The decision on where to focus the comparison can be assisted by considering the use of dense time-series comparisons of satellite sensor data and derived products (e.g., the NDVI). This approach was taken in the case of the mangrove dieback, where the NDVI time-series (and also knowledge) indicated the time periods to compare LCCS component codes and EVs before and after the event (i.e., 2014 and 2016). Further comparisons 
between two longer time-separated periods can also be used to track the recovery (or otherwise) of mangroves over time. Consideration generally should also be given to the temporal analysis of data, such as the NDVI, over time using algorithms such as the BFAST [12]. These can allow the targeting of the comparisons between $t_{1}$ and $t_{2}$.

The approach to identifying change differs from more traditional change detection procedures that typically compare classifications or measures (e.g., indices) generated or derived from an entire scene (or combination of scenes). These tend not to consider that change is often specific to a variable within and between different land covers and that multiple changes are occurring at the same time but also over different time frames. EODESM is therefore particularly beneficial, as a wide range of changes can be captured but also combined. As an example, information on hydroperiod change between two years can be combined with that of water extent change mapped between two sub-annual periods (e.g., weeks, months or each time a satellite image is acquired).

The EODESM system also allows for the detection and description of change to generate historical and potentially near real-time change descriptions. In the case of the mangrove dieback along the coastline of the Gulf of Carpentaria, evidence within or accessible through DEA included the change from aquatic (semi) natural vegetation to water (overlying mudflats). Furthermore, in areas where mangroves had retained a canopy cover, a decrease from a closed to a sparser canopy-covered forest was observed. No other changes were detected, as all other layers were generated from a single year. The transition from vegetation to non-vegetation and the loss of canopy could indicate deforestation, but this is unlikely given that mangroves are protected in Australia and observations post-dieback indicated canopy height did not decrease significantly. Alternative changes would be defoliation or dieback, but the introduction of Advanced Land Observing Satellite (ALOS-2) Phased Arrayed L-band Synthetic Aperture Radar (PALSAR-2) data prior to and following the dieback indicated a decrease in L-band backscatter and hence a loss of moisture content within the woody biomass. In the case of the Burdekin catchment, the loss of water between 2009 and 2016 was indicated by a change from non-vegetated (i.e., water) to vegetated and also the transition (at the margins) from aquatic to 'terrestrial' vegetation as lake levels progressively decreased over time. This sequence indicated colonisation by vegetation of what was assumed to be relatively shallow water. In both selected case studies, the integration of additional layers acquired at appropriate time points would benefit the evidence-based approach to change detection.

\subsection{Application within the DEA}

Within this study, the DEA datasets were capable of classifying changes in the extent of vegetation cover and hydroperiod within the EODESM system. These datasets are available in yearly summaries (from 1987 to present), and potentially at finer temporal scales, and form a significant part of the system's ability to describe the state and change across the Australian landscape. However, to provide more detailed descriptions of land covers, additional datasets not currently part of DEA were accessed, with these including the cultivated and urban datasets provided by ABARES and TERN's CVH. It is not necessary for these to be are hosted within the DEA environment, but they are critical to the base functionality of the EODESM system, and consideration needs to be given to how best to achieve access in an operational manner. While they are freely distributed by their respective suppliers, a more formal engagement with the parties responsible may provide benefits to DEA and the suppliers in terms of the validation (and error estimation) of datasets, public visibility of the datasets, and the potential to affect how often these datasets are maintained and updated.

Within EODESM, the land cover and change classifications were generated entirely from EVs, which were both continuous and thematically coded (e.g., the ABARE Cultivated Layer). In several cases (e.g., for WOfS, TERN CVH and National Mangroves), uncertainty estimates were available, although these were based on, for example, a selection of sites for which higher resolution data (e.g., LIDAR CVHs) were available. The overall class accuracies are therefore accumulated from-and are therefore dependent upon-the accuracy of the input layers, noting that these will vary both 
spatially and temporally. A criterion for using these layers is that they were available nationally. However, future efforts are now focusing upon the generation of spatially explicit accuracy layers that can give estimates of uncertainty at the pixel level and confidence in the classifications generated, including at the national level. A step towards this also has been the development of the EarthTrack mobile application (earthtrack.aber.ac.uk), which facilitates the ground level collection and public dissemination of land cover and change data in near real-time and according to the FAO LCCS Version 2 taxonomy and the TERN mangrove portal [29], which disseminates a diverse range of ground and airborne datasets to support national mangrove mapping and monitoring efforts.

As the EODESM system is not tied to comparisons over a fixed period of time, change metrics generated by the system have the potential to highlight events on the landscape at a variety of temporal scales. Dramatic changes, such as defoliation due to pests and damage from bushfires or flooding, occur over potentially much shorter timescale than the effects of long-term reduction in rainfall, but both scales can be monitored simply by specifying the beginning and end of the comparison time period to before and after such events. In this case, DEA could implement official products classifying the state of vegetation (according to the LCCS) at the continental scale with annual products (which is the current preference for major DEA products) and provide users with the ability to focus on areas of interest to generate LCCS classifications and change metrics for different time-periods (across multiple years, or within year change). However, one of the challenges to be faced will be to rank the identified changes and separate true changes (where a real and meaningful event or change in land use has taken place) from the many natural, seasonal and land management changes which will also be identified by the system.

The EODESM system has been shown to work under the DEA and National Computational Infrastructure (NCI) environments, but while the base inputs provided to the system are already generating useful data on the state of the landscape and the state of change, there is significant potential to enhance the capability of the generated products through the incorporation of additional datasets. Vegetation cover, height, hydroperiod, urban and cultivated environments are the base requirements (i.e., for LCCS Level 3). However, additional datasets should be explored, such as the use of high-dimensional pixel composites/statistics of time series to distinguish urban and cultivated environments $[25,30]$

The inclusion of datasets that can be retrieved periodically, ideally derived from the Landsat archive, would enable the robust assessment of the state of the landscape. Moreover, the retrieval of additional variables such as AGB (e.g., as derived from combinations of ALOS-1/2 PALSAR-1/2, Landsat sensor and ICESAT-1/2 or GEDI data) and water turbidity and depth (from optical sensors) would further provide information to describe evidence-based change. Additional work is required to better inform the EODESM system with respect to species distribution of vegetation, road networks, bare surface classifications and more. The LCCS standard includes numerous physical descriptors of the landscape (see Figure 1), and all of them can be incorporated into EODESM to form a better understanding of the state of the landscape both past and present, and to better predict how changes may affect the landscape in the future. The results for Lake Ross in the Townsville-Ayr region and the mangrove dieback around the mouth of the Norman river in the Leichhardt region show that both the WOfS and vegetation fractional cover are already useful layers that can be exploited to detect multiple changes across the Australian landscape.

There are several advantages to using the EODESM approach within DEA. The national availability of datasets and the 30-year archive of data make it possible to generate land cover and land cover change maps for any spatial extents within Australia and for any time period, and to compare changes between periods that are separated by variable time intervals. DEA also has computing capacity to generate LCCS classifications at a national (continental) level. Layers that are currently available on an annual basis (from 1987 to the present) are hydroperiod and fractional vegetation cover, whilst ITEM has been generated from an interannual time-series of Landsat sensor data in order to maximize the capture of the landscape at the lowest tides. Other layers that can be used as direct input to EODESM 
are either under review for final publishing on DEA or are separately maintained products. As such, while EODESM has been successfully tested using data on DEA, the publication of more EV data layers at a national scale would facilitate comprehensive classifications of land cover and change using EODESM.

\section{Conclusions}

This research provides evidence of the capability of the EODESM approach to deliver consistent classifications of land covers and change dynamics over diverse Australian landscapes. The research has established that the EODESM system can be integrated within the framework of the ODC, and applied to diverse landscapes, as demonstrated for Australia through DEA. EODESM therefore provides an option for the mapping of evidence-based land covers and change at a national level and for multiple time instances. The maps generated are at a higher spatial resolution than most current Australian and global land cover classifications, and the use of national EVs results in seamless mapping between tiles. The information content can also be increased by generating or accessing additional EVs. Mapping accuracy can be assessed using higher-resolution datasets, but there is a potential for validation using mobile applications or higher-resolution thematic maps (e.g., vegetation height and cover, water extent and turbidity) generated from airborne LiDAR or drone imagery; additionally, the latter can also be used to generate higher-resolution LCCS classifications for validation.

The EODESM system allows for the classifications of land covers for two points in time (determined by the user), and it can also detect basic and more advanced evidenced-based change alerts, as demonstrated for the Townsville-Ayr region (hydroperiod and vegetation/water change) and the Gulf of Carpentaria (mangroves). Change events and processes can also be identified within DEA through the analysis of the dense time series of Landsat sensor data and/or derived products (e.g., NDVI), thereby informing the time steps with which to best describe these changes using EODESM. A benefit of the approach is that new algorithms for generating EVs can be introduced and the resulting layers (e.g., hydroperiods) then inserted into EODESM to produce revisions of the classifications, including historically.

As result of this use case, we recommend (a) a national demonstration of the approach to land cover and change classification using EVs retrieved at the continental level as inputs to EODESM and within the framework of DEA; (b) the increase of the capacity for generating consistent, nationally available and temporally variable data layers (e.g., urban extent, cultivated area) for improved classifications; and (c) the advancement of the use of airborne (including drone) and mobile applications for validating classifications and advancing the retrieval of EVs.

Author Contributions: Conceptualisation, G.M.; Formal analysis, N.M., A.S. and C.O.; Investigation, C.K. and B.T.; Methodology, L.L.; Project administration, N.M.; Software, D.C., P.B., B.T. and B.L.; Visualization, R.L.

Funding: EODESM represents an advancement of the EODHaM system, which was developed originally through through the European Community's Seventh Framework Programme, within the FP7/SPA.2010.1.1-04: "Stimulating the development of GMES services in specific area", under grant agreement 263435 for the project 'Biodiversity Multi-Source Monitoring System: From Space To Species' (BIO SOS). The European Union's Horizon 2020 research and innovation program under grant agreement no. 641762 supported the development of EODESM with specific application to protected areas. The European Research Development Fund (ERDF) Sêr Cymru II program award (80761-AU-108; Living Wales) to Richard Lucas allowed continued development for application at national levels and realisation of the EarthTrack mobile app. Geoscience Australia provided support to demonstrate application within the Open Data Cube environment.

Acknowledgments: This paper was published with the permission of the CEO, Geoscience Australia. The authors would like to thank the considerable contributions made through the BIOSOS, ECOPOTENTIAL and Living Wales projects and thank PlanetLab for allowing access to the RapidEye data for Lake Ross.

Conflicts of Interest: The authors declare no conflict of interest. 


\section{References}

1. Geoscience Australia. 2011. Available online: https://ecat.ga.gov.au/geonetwork/srv/eng/catalog.search\# /metadata/71069 (accessed on 16 October 2019).

2. International Organization for Standardization. 2018. Available online: https://www.iso.org/standard/44342. html (accessed on 16 October 2019).

3. Atyeo, C.; Thackway, R. A Field Manual for Describing and Mapping Revegetation Activities in Australia; Bureau of Rural Sciences: Canberra, Australia, 2009.

4. Lewis, A.; Oliver, S.; Lymburner, L.; Evans, B.; Wyborn, L.; Mueller, N.; Raevksi, G.; Hooke, J.; Woodcock, R.; Sixsmith, J.; et al. The Australian geoscience data cube-Foundations and lessons learned. Remote Sens. Environ. 2017, 202, 276-292. [CrossRef]

5. Lucas, R.M.; Blonda, P.; Bunting, P.; Jones, G.; Inglada, J.; Aria, M.; Kosmidou, V.; Petrou, Z.I.; Manakos, I.; Adamo, M.; et al. The Earth Observation Data for Habitat Monitoring (EODHAM) System. Int. J. Appl. Earth Obs. Geoinform. 2014, 37, 17-28. [CrossRef]

6. Lucas, R.M.; Medcalf, K.; Brown, A.; Bunting, P.; Breyer, J.; Clewley, D.; Keyworth, S.; Blackmore, P. Updating the Phase 1 habitat map of Wales, UK, using satellite sensor data. ISPRS J. Photogramm. Remote Sens. 2011, 66, 81-102. [CrossRef]

7. EcoPotential NGO. Available online: https://www.ecopotential-project.eu (accessed on 16 October 2019).

8. Lucas, R.M.; Mitchell, A. Integrated Land Cover and Change Classifications. In The Roles of Remote Sensing in Nature Conservation: A Practical Guide and Case Studies; Díaz-Delgado, Lucas, R., Hurford, C., Eds.; Springer: Cham, Switzerland, 2017; pp. 295-308.

9. Lucas, R.M. The Earth Observation Data for Ecosystem Monitoring (EODESM). Available online: https: //essilab.wixsite.com/eodesm (accessed on 16 October 2019).

10. Bunting, P.; Clewley, D.; Lucas, R.M.; Gillingham, S. The Remote Sensing and GIS Software Library (RSGISLib). Comput. Geosci. 2014, 62, 206-226. [CrossRef]

11. Bunting, P.; Gillingham, S. The KEA image file format. Comput. Geosci. 2013, 57, 54-58. [CrossRef]

12. Verbesselt, J.; Hyndman, R.; Zeileis, A.; Culvenor, D. Phenological change detection while accounting for abrupt and gradual trends in satellite image time series. Remote Sens. Environ. 2010, 114, 2970-2980. [CrossRef]

13. Tarantino, C.; Adamo, M.; Lucas, R.; Blonda, P. Detection of changes in semi-natural grasslands by Cross Correlation Analysis with WorldView-2 images and new Landsat 8 data. Remote Sens. Environ. 2016, 175, 65-72. [CrossRef] [PubMed]

14. Gill, T.; Johansen, K.; Phinn, S.; Trevithick, R.; Scarth, P.; Armston, J. A method for mapping Australian 584 woody vegetation cover by linking continental-scale field data and long-term Landsat time series. Int. J. Remote Sens. 2017, 38, 679-705. [CrossRef]

15. Sagar, S.; Roberts, D.; Bala, B.; Lymburner, L. Extracting the intertidal extent and topography of the Australian coastline from a 28 year time series of Landsat observations. Remote Sens. Environ. 2017, 195, 153-169. [CrossRef]

16. Lymburner, L.; Bunting, P.; Lucas, R.; Scarth, P.; Alam, I.; Phillips, C.; Ticehurst, C.; Held, A. Mapping the multi-decadal mangrove dynamics of the Australian coastline. Remote Sens. Environ. 2019. [CrossRef]

17. Mueller, N.; Lewis, A.; Roberts, D.; Ring, S.; Melrose, R.; Sixsmith, J.; Lymburner, L.; McIntyre, A.; Tan, P.; Curnow, S.; et al. Water observations from space: Mapping surface water from 25 years of Landsat imagery across Australia. Remote Sens. Environ. 2016, 174, 341-352. [CrossRef]

18. ABARES. The Australian Land Use and Management Classification Version 8; CC BY 3.0; Australian Bureau of Agricultural and Resource Economics and Sciences: Canberra, Australian, 2016.

19. Scarth, P.; Armston, J.; Lucas, R.; Bunting, P. A Structural Classification of Australian Vegetation Using ICESat/GLAS, ALOS PALSAR, and Landsat Sensor Data. Remote Sens. 2019, 11, 147. [CrossRef]

20. Australian DoEE. Available online: https://www.environment.gov.au/ (accessed on 16 October 2019).

21. Bunting, P.; Rosenqvist, A.; Lucas, R.; Rebelo, L.M.; Hilarides, L.; Thomas, N.; Hardy, A.; Itoh, T.; Shimada, M.; Finlayson, C. The Global Mangrove Watch-a New 2010 Baseline of Mangrove Extent. Remote Sens. 2018, 10, 1669. [CrossRef] 
22. Duke, N.C.; Kovacs, J.M.; Griffiths, A.D.; Preece, L.; Hill, D.J.; Van Oosterzee, P.; Mackenzie, J.; Morning, H.S.; Burrows, D. Large-scale dieback of mangroves in Australia's Gulf of Carpentaria: A severe ecosystem response, coincidental with an unusually extreme weather event. Mar. Freshw. Res. 2017, 68, 1816-1829. [CrossRef]

23. Clewley, D.; Bunting, P.; Shepherd, J.; Gillingham, S.; Flood, N.; Dymond, J.; Lucas, R.; Armston, J.; Moghaddam, M. A Python-Based Open Source System for Geographic Object-Based Image Analysis (GEOBIA) Utilizing Raster Attribute Tables. Remote Sens. 2014, 6, 6111-6135. [CrossRef]

24. Shepherd, J.D.; Bunting, P.; Dymond, J. Operational large-scale segmentation of imagery based on iterative elimination. Remote Sens. 2019, 11, 658. [CrossRef]

25. Roberts, D.; McIntyre, A.; Mueller, N. High-dimensional pixel composites from earth observation time series. IEEE Trans. Geosci. Remote Sens. 2017, 55, 6254-6264. [CrossRef]

26. Hacker, J. Targeted Airborne Data. Available online: http://wiki.auscover.net.au/wiki/Targeted_Airborne_ Data. (accessed on 16 October 2019).

27. Lucas, R.; Finlayson, C.M.; Bartolo, R.; Rogers, K.; Mitchell, A.; Woodroffe, C.; Asbridge, E.; Ens, E. Historical perspectives on the mangroves of Kakadu National Park. Mar. Freshw. Res. 2017, 69, 1047-1063. [CrossRef]

28. PlanetLabs. Available online: https://www.planet.com/ (accessed on 16 October 2019).

29. The Terrestrial Environment Research Network (TERN) Mangrove Data Portal. Available online: http://wiki. auscover.net.au/wiki/TERN_Mangrove_Data_Portal_and_Monitoring_System (accessed on 25 June 2019).

30. Roberts, D.; Dunn, B.; Mueller, N. Open Data Cube Products Using High-Dimensional Statistics of Time Series. In Proceedings of the IGARSS 2018-2018 IEEE International Geoscience and Remote Sensing Symposium, Valencia, Spain, 30 June 2018; pp. 8647-8650.

(C) 2019 by the authors. Licensee MDPI, Basel, Switzerland. This article is an open access article distributed under the terms and conditions of the Creative Commons Attribution (CC BY) license (http://creativecommons.org/licenses/by/4.0/). 